\title{
Isolation of Janthinobacterium lividum from early onset neonatal sepsis patients in Malaysia
}

\author{
Sa'adatu Haruna Shinkafi', Shu'aibu Umar', Vasantha Kumari Neela², Sabariah Moh'd Noordin², \\ Syafinaz Amin Noordin², Shuaibu Abdullahi Hudu ${ }^{4}$, Zurina Zainudin ${ }^{5}$
}

1. Department of Medical Microbiology and Parasitology, Usmanu Danfodiyo University Teaching Hospital, Sokoto-Nigeria.

2. Department of Medical Microbiology and Parasitology, Faculty of Medicine and Health Sciences, Universiti Putra Malaysia.

3. Department of Haematology, Faculty of Medicine and Health Sciences, Universiti Putra Malaysia.

4. Department of Medical Microbiology and Parasitology, College of Medicine and Health Sciences, Usmanu

Danfodiyo University, Sokoto-Nigeria.

5. Department of Paediatrics, Faculty of Medicine and Health Sciences, Universiti Putra Malaysia.

\begin{abstract} collected were equally cultured and incubated in automated BACTEC system.

DOI: https://dx.doi.org/10.4314/ahs.v19i3.11 abs.v19i3.11

\section{Introduction}

Neonatal sepsis is usually characterized by bacteraemia in addition to clinical symptoms resulting from infection with microorganism or its toxic products. Depending on the time of onset it can be classified as early onset (EONS) when sepsis occurs within the first 3 days of life
\end{abstract}

Background: The term early onset neonatal septicaemia (EONS) refers to invasive bacterial infections that primarily involve the blood stream of neonates during the first 3 days of life. Although early onset neonatal septicaemia is relatively uncommon, it may be associated with case fatality rates of $15-30 \%$ and substantial morbidity in surviving infants.

Objectives: This study describes an unusual septicaemia cases with Janthinobacterium lividum in neonatal Intensive Care Units.

Methods: Bacterial causes of early onset neonatal sepsis in Kuala Lumpur Hospital Malaysia were investigated using broad range 16S rDNA PCR and sequencing. The bacterial DNA was isolated directly from blood without pre-incubation. All samples

Results: Two hundred and fifty two neonates were recruited in this study with mean (SD) gestational age of 35.9. Neonates with J. lividum infection lacked microbiological evidence of septicaemia as their blood culture yielded no bacterial growth. However, the PCR analysis of these samples yielded $1100 \mathrm{bp}$ corresponding to bacteria species.

Conclusion: This study demonstrates the value of PCR in detecting bacteria where special growth requirement is involved.

Keywords: Janthinobacterium lividum, neonatal septicaemia, neonatal intensive care units.

Cite as: Shinkafi SH, Umar S, Neela VK, Noordin SM, Noordin SA, Hudu SA, Zainudin Z. Isolation of Janthinobacterium lividum from early onset neonatal sepsis patients in Malaysia. Afri Health Sci. 2019;19(3): 2378-2389. bttps:/ / dx.doi.org/10.4314/
Corresponding author:
Zurina Zainudin,
Department of Paediatrics,
Faculty of Medicine and Health Sciences,
Universiti Putra Malaysia
43400 UPM Serdang
Selangor Darul Ehsan
Tel: +60389472619
Email: zaizurina@upm.edu.my

or late onset (LOS) if symptom appears beyond 72 hours of life. The incidence of EONS is globally estimated at 3 million cases per live birth ${ }^{1}$. The incidence of EONS in South-East Asia is 4-10 per 1000 live birth ${ }^{2}$. The most frequently encountered organisms in the cases of EONS as reported from previous studies were Group B Streptococcus (GBS), Escheria. Coli and Klebsiella species $^{3,4}$.

Early onset neonatal sepsis is often the most common disease presumably diagnosed in the neonatal intensive care units (NICU). This is mainly because of the signs and symptoms of disease are non-specific; the gold standard for diagnosis of neonatal sepsis is blood culture. However, the incubation period of 24-48 hours needed to report preliminary blood culture result, a low bacterial copy and inability to obtain sufficient amount of blood sample from neonates in addition to fastidiousness and

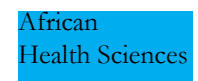

2378
(C) 2019 Shinkafi et al. Licensee African Health Sciences. This is an Open Access article distributed under the terms of the Creative commons Attribution License (https://creativecommons.org/licenses/BY/4.0), which permits unrestricted use, distribution, and reproduction in any medium, provided the original work is properly cited. 
special growth requirements exhibited by some bacteria and prior maternal antibiotic administration makes blood culture less suitable in the diagnosis of EONS. Molecular assays for detection of neonatal blood stream pathogens are promising and can serve as rapid and sensitive methods of diagnosing neonates with sepsis. Thus, it reduces the prolong hospital stay; lessen the overall medical cost and the emotional burdens of the families. A negative blood culture is commonly reported especially in cases of early onset neonatal sepsis in NICU, despite the clinical features suggestive of sepsis. Nonetheless, these neonates might not actually be free of infection, but the special growth requirement of the offending pathogen might have been the resulting cause of culture negative result. This study described an unusual septicaemia cases with Janthinobacterium lividum in neonatal intensive care units. The outcome of the study may lead to an in-depth analysis and modification of current approach of frequently reported negative blood culture result.

\section{Material and methods \\ Ethical approval}

This study was approved by the National Medical Research Register -National Institute of Health (NMRRNIH) NMRR-ID: NMRR-12-631-10838 and the Research Ethic Committee of Universiti Putra Malaysia reference number: UPM/FPSK/100-9/2-MJKEtikaPen (Lect JPED_April (12)01.

\section{Patients}

Study population included neonates of age 0 to 48 hours old who were admitted to the neonatal intensive care units (NICUs) between November 2012 and February 2014.

\section{Inclusion criteria}

Neonates who were clinically diagnosed as having sepsis and those who presented with at least one of the signs and symptoms of neonatal sepsis such as tachypnea (respiratory rate $>60$ breath per minute), presence of flaring, grunting, chest recessions, fever (>380 C), poor feeding, cyanosis, seizure, lethargy, etc. were included into the study.

\section{Exclusion criteria}

All babies born prior to 32 weeks of gestation and/or with birth weight of less than $1500 \mathrm{gm}$ were excluded. Neonates who were later found to have perinatal asphyx- ia, congenital cyanotic heart disease or multiple congenital abnormalities to avoid confounding factors as well as numerous missing hospital data were also excluded from the study.

\section{Clinical data}

Extensive dataset was collected using a standardized data extraction form. Additional data were extracted from the maternal hospital records in a retrospective study.

\section{Specimen collection}

At the end of all clinical evaluation by the consulting clinician on duty, two hundred and fifty two blood specimens $(4 \mathrm{ml})$ were drawn from eligible neonate prior to antibiotic administration. Approximately, one millilitre $(1 \mathrm{ml})$ of the blood sample collected was inoculated into paediatric blood culture bottle and transported to microbiology laboratory for immediate incubation in automated BACTEC system. Positive samples when alerted were identified and processed accordingly by the laboratory staff in charge and results remained unknown to the researcher until the end of the study. From the remaining blood, $0.5 \mathrm{ml}$ was transferred into standard $0.5 \mathrm{ml} \mathrm{K3}$ EDTA sample tube and sent to the research laboratory at the Department of Medical Microbiology and Parasitology, Faculty of Medicine and Health Sciences Universiti Putra Malaysia for molecular based identification.

The remaining $2 \mathrm{ml}$ of blood of each blood sample was transferred into standard $2 \mathrm{ml}$ vacutainer K3 EDTA tube and transported to the haematology laboratory Hospital Kuala Lumpur and were processed for automated full blood count (FBC) within one hour of sample receipt. Manual blood film for immature to total neutrophil ratio was obtained from a pair of slides prepared per sample. The preparation of slides was done in accordance with the Clinical and Laboratory Standard Institute (CLSI) protocol. White cell count (WBC) differential count was done on each film by a qualified haemato-pathologist and medical laboratory scientist. After staining, the monolayer at the tail end of the smear was examined using 100X (oil immersion objective). Manual absolute neutrophils count (ANC) was calculated as automated corrected WBC count (if required) X ( $\%$ segmented neutrophils $+\%$ Immature granulocytes/100. Immature granulocytes consist of promyelocytes, myelocytes, and metamyelocytes and bands cells. Cells were considered as band if there was no nuclear segmentation. 
The blood samples for molecular study were stored in the refrigerator at $4^{0} \mathrm{C}$ for 72 hours or until there was a clear separation into plasma and red cells layers. The plasma was carefully removed into a sterile $1.5 \mathrm{ml}$ tube and stored at $-20^{\circ} \mathrm{C}$, until further analysis. Deoxyribonucleic acid (DNA) was extracted from $200 \mu$ l of the resulting plasma using QIAamp DNA mini kit (Qiagen Inc., Hilden, Germany) according to manufacturer's guidelines. The extracted DNA was eluted in $100 \mu$ l elution buffer and stored at $-20^{\circ} \mathrm{C}$ until further analysis. DNA amplification was carried out in Biometra thermocycler (Biometra GmbH, Germany). Polymerase chain reaction (PCR) comprised of two oligonucleotide universal primers 5'-TGAAGAGT'TTGATCATGGCTCAG-3' and 5'-TCGTTGCGGGACT'TAACC-3 (IDT Technology, Singapore) as previously reported ${ }^{5}$. The PCR products amplified were electrophoresed in $1.2 \%$ gel at $70 \mathrm{~V}$ for 90 minutes. The gel was visualized using gel documentation system (Bio Rad Laboratory Inc.) Products at the expected band size of $1100 \mathrm{bp}$ were considered positive. Bacterial DNA extracted from American Type Culture Collection (ATCC) Staphylococcus aureus was used as positive control. Negative control consisted of all PCR components except the template DNA.

The resulting products were purified using PCR purification kit (Vivantis ${ }^{\circledR}$ Technologies, Sdn Bhd, Malaysia) as per manufacturer's instruction.Purified products were sequenced commercially. Bidirectional sequencing was performed on the $1100 \mathrm{bp} 16 \mathrm{~S} \mathrm{rDNA}$ core region of PCR positives samples with forward primer 5'-TGAAGAGTTTGATCATGGCTCAG-3' and reverse primer 5'-TCGTTGCGGGACTTAACC-3(DNA Sequencer ABI 3730-XL, 1st BASE Company, Singapore). Traces were analysed with Applied Bioscience (ABI) sequence-analysis software, version 5.2.0. The good quality sequences were aligned using alignment tool in the SDSC Biology work bench 3.2. The aligned sequences were blasted against a quality controlled 16S rRNA gene library (Sepsis test-blast.net) to identify the organism. Genus and species identification were presumed to be correct for the isolate with sequence identity of $\geq 97 \%$ to reference strain in the data base.

\section{Development of primers for species-specific PCR assays}

We retrieved sequence of the for J. Lividum chitinase (Chi 69) gene complete cds (U07025) from the GenBank database, Designed primers specific for J. lividum. Primers JF'-5'-GACAAATCCGAATTCGCCCG-3' and JR'-5'CGCCGCCTTCAACTTT'TTCA-3'. These primers were optimised to amplify 151bp between positions 1305-1456 of the chitinase gene in J. lividum. Bacterial DNA from samples whose broad range PCR was positive for J. lividum were amplified with these specific primers. The PCR reactions of $25 \mu \mathrm{l}$ volume consisted of $12.5 \mu \mathrm{l}$ of master mix (Promega, USA), $0.2 \mu \mathrm{M}$ of each primers, $10 \mu \mathrm{l}$ of template DNA and $2 \mu \mathrm{l}$ of sterile milliQ water. The thermocycling condition included an initial denaturation at $94^{\circ} \mathrm{C}$ for 4 minutes 35 cycles of $94^{\circ} \mathrm{C}$ for 60 seconds, $51^{\circ} \mathrm{C}$ for 30 seconds, $72^{\circ} \mathrm{C}$ for 2 minutes and a final extension at $72^{\circ} \mathrm{C}$ for 10 minutes. The PCR products were ran in $1.2 \%$ gel and electrophoresed at $70 \mathrm{~V}$ for 90 minutes. The gel was visualized using gel documentation system (Bio Rad Laboratory Inc.) Products at the expected band size of 151bp were considered positive. Amplification products were directly sequenced as mentioned earlier and blasted against the Basic Local Alignment Search Tool (BLAST) search algorithm.

\section{Antibiotic resistance gene assays}

The PCR primers for the antibiotic resistance blaZ and aac (6')-aph (2') that encodes for amino glycosides-modifying enzyme which confers resistance to Penicillin and Gentamycin were used to determine the susceptibility of J. lividum to antibiotic administered to the neonates under study. BlaZ-F'-5'-ACTTCAACACCTGCTGCTTTC-3' and blaZ-R'-5'-TGACCACT'TTTATCAGCAACC-3' amplifies 173bp of blaZ. While aac(6')-aph(2')-F'-5'-TTGGGAAGATGAAGT'TT'TAGA-3' and aac(6')-aph(2')R'-5'-CCT'T'TACTCCAATAAT'T'TGGCT-3' amplifies 174bp of aac(6')-aph(2') resistance gene. PCR amplifications were performed following standardized protocol described previously ${ }^{6}$.

\section{Data analysis}

All data from the data extraction forms were entered into Statistical Package for the Social Sciences (SPSS) database. Data analysis was by descriptive and inferential statistics using SPSS for Windows, Version 20.0. Armonk, NY: IBM Corp. 


\section{Results}

\section{General data}

There were 252 neonates who had their clinical data and blood sample collected for blood culture, PCR and other laboratory analysis. Among these, 22 had J. lividum in their blood samples. Details of the demographic characteristics of neonates with J. lividum infection are presented in Table 1.

Table 1: Demographic and birth characteristics data of neonates with J. lividum septicaemia $(n=22)$

\begin{tabular}{|c|c|c|c|c|c|}
\hline Sex & $\begin{array}{ll}\begin{array}{l}\text { Mode } \\
\text { delivery }\end{array} & \text { of } \\
\end{array}$ & $\begin{array}{l}\text { Gestational } \\
\text { age(Weeks) }\end{array}$ & $\begin{array}{l}\text { Birth weight } \\
\text { (kg) }\end{array}$ & $\begin{array}{ll}\begin{array}{l}\text { Age } \\
\text { presentation(Hours) }\end{array} & \text { at }\end{array}$ & $\begin{array}{ll}\begin{array}{l}\text { Reason } \\
\text { admission }\end{array} & \text { for } \\
\end{array}$ \\
\hline Male & SVD & 33.0 & 1.46 & 1.00 & $\begin{array}{l}\text { Prematurity and } \\
\text { Presumed sepsis }\end{array}$ \\
\hline Male & SVD & 39.0 & 2.73 & 13.00 & Presumed sepsis \\
\hline Female & LSCS & 35.0 & 3.42 & 28.00 & Presumed sepsis \\
\hline Male & Instrumental & 38.0 & 3.30 & 1.00 & others \\
\hline Female & SVD & 33.0 & 1.96 & 1.00 & Presumed sepsis \\
\hline Female & SVD & 39.0 & 2.99 & 20.00 & Presumed sepsis \\
\hline Male & Instrumental & 39.0 & 3.31 & 7.00 & Presumed sepsis \\
\hline Male & LSCS & 34.0 & 1.45 & 1.50 & $\begin{array}{l}\text { Respiratory } \\
\text { distress } \\
\text { syndrome }\end{array}$ \\
\hline Female & LSCS & 39.0 & 2.90 & 44.00 & Presumed sepsis \\
\hline Female & Instrumental & 39.0 & 3.27 & 1.00 & Presumed sepsis \\
\hline Female & LSCS & 37.5 & 3.17 & 24.00 & Presumed sepsis \\
\hline Male & SVD & 33.0 & 1.76 & 1.00 & $\begin{array}{l}\text { Prematurity and } \\
\text { Presumed sepsis }\end{array}$ \\
\hline Male & LSCS & 38.0 & 2.95 & 1.00 & others \\
\hline Male & LSCS & 35.0 & 1.89 & 24.00 & $\begin{array}{l}\text { Prematurity and } \\
\text { Presumed sepsis }\end{array}$ \\
\hline Male & LSCS & 35.0 & 1.81 & 24.00 & $\begin{array}{l}\text { Prematurity and } \\
\text { Presumed sepsis }\end{array}$ \\
\hline Female & SVD & 38.0 & 2.60 & 2.00 & Presumed sepsis \\
\hline Female & LSCS & 34.0 & 1.52 & 2.00 & $\begin{array}{l}\text { Prematurity and } \\
\text { Presumed sepsis }\end{array}$ \\
\hline Male & LSCS & 34.0 & 1.77 & 2.00 & $\begin{array}{l}\text { Prematurity and } \\
\text { Presumed sepsis }\end{array}$ \\
\hline Male & LSCS & 35.0 & 2.55 & 17.00 & Presumed sepsis \\
\hline Male & LSCS & 35.0 & 2.55 & 3.00 & $\begin{array}{l}\text { RDS and } \\
\text { Presumed sepsis }\end{array}$ \\
\hline Male & LSCS & 38.0 & 4.35 & 1.50 & $\begin{array}{l}\text { Prematurity and } \\
\text { Presumed sepsis }\end{array}$ \\
\hline Female & LSCS & 35.0 & 2.90 & 1.00 & $\begin{array}{l}\text { Prematurity and } \\
\text { RDS }\end{array}$ \\
\hline
\end{tabular}

SVD: Spontaneous Vaginal Delivery, LSCS: Lower segment Caesarean section, RDS: Respiratory distress syndrome

The gestational age of neonates with J. lividum septicaemia ranges from 32-40 weeks and the mean \pm SD gestational age is 35.9 weeks \pm 2.56 . Among these, $54.5 \%$ were born premature with tachypnea as the commonest presenting clinical characteristics as presented in Table 2. Thirteen (59.1\%) Males and nine (40.9\%) Females were positive for J. lividum infection. About half of these new- borns required oxygen support with seven $(32 \%)$ had non-invasive ventilator support. All neonates were discharged alive and without any neonatal complication. Risk factors predisposed to neonatal sepsis is presented in Table 3. It was determined that leaking liquor, urinary tract infection and intrapartum fever are among the risk factors associated with J. lividum neonatal sepsis. 
Table 2: Clinical presentation of neonates with J. lividumsepticaemia $(n=22)$

\begin{tabular}{ll}
\hline Clinical presentation & n (\%) \\
\hline Tachypnea & $16(72.7)$ \\
Grunting & $7(31.8)$ \\
Chest recession & $7(31.8)$ \\
Fever $\left(>38^{\circ} \mathrm{C}\right)$ & $3(13.6)$ \\
Nasal flaring & $6(27.3)$ \\
Vomiting & $4(18.8)$ \\
Lethargy & $2(9.1)$ \\
Prematurity & $12(54.5)$ \\
Low birth weight & $3(13.6)$ \\
\hline
\end{tabular}

*Some neonates presented more than one clinical sign;

Prematurity: Baby born less than 37 week

Table 3: Risk factors associated with $J$. lividum early onset neonatal septicaemia (n-22)

\begin{tabular}{ll}
\hline Risk factors & n (\%) \\
\hline Leaking liquor $>18$ hurs & $6(27.3)$ \\
Premature prelabour rupture of membrane & $2(9.1)$ \\
Meconium stained liquor & $4(18.2)$ \\
Foul smelly liquor & $1(4.5)$ \\
Chorioamnionitis & $1(4.5)$ \\
Maternal urinary tract infection & $6(27.3)$ \\
Intrapartum fever & $4(18.2)$ \\
\hline
\end{tabular}




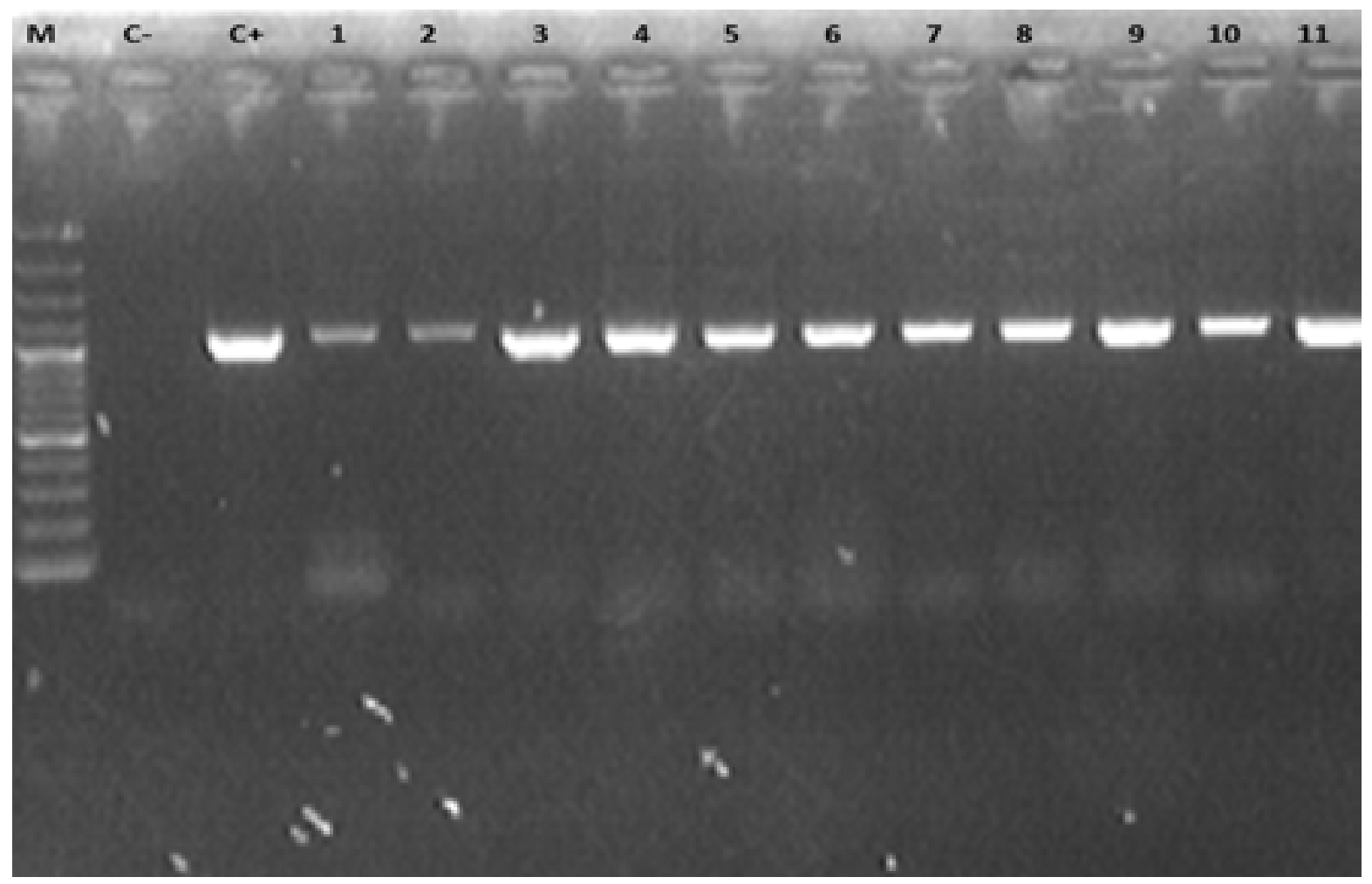

Figure 1: Amplification of 1100bp 16S rRNA from blood samples (M: 100bp marker)

\section{PCR and sequencing}

All 22 neonates with J. lividum infection lacked microbiological evidence of septicaemia as their blood culture yielded no bacterial growth. However, the PCR analysis of these samples yielded $1100 \mathrm{bp}$ corresponding to bacteria specie or genera as shown in Figure 2. Following 16S rDNA sequencing and BLAST search algorithm of GenBank a quality controlled 16S rRNA gene library (Sepsis test-blast.net), the best matches and sequence homologies were that of J. lividum (Figure 3). Other samples negative by PCR were equally negative by culture.

Table 4 shows the analysis of laboratory parameters of the 22 neonates with J. lividum septicaemia, analysis of the commonly utilised hematologic parameters in diagnosing neonatal septicaemia showed abnormality in some haematological parameters and C-reactive protein (CRP) with majority of neonates having parameters within normal limit. 


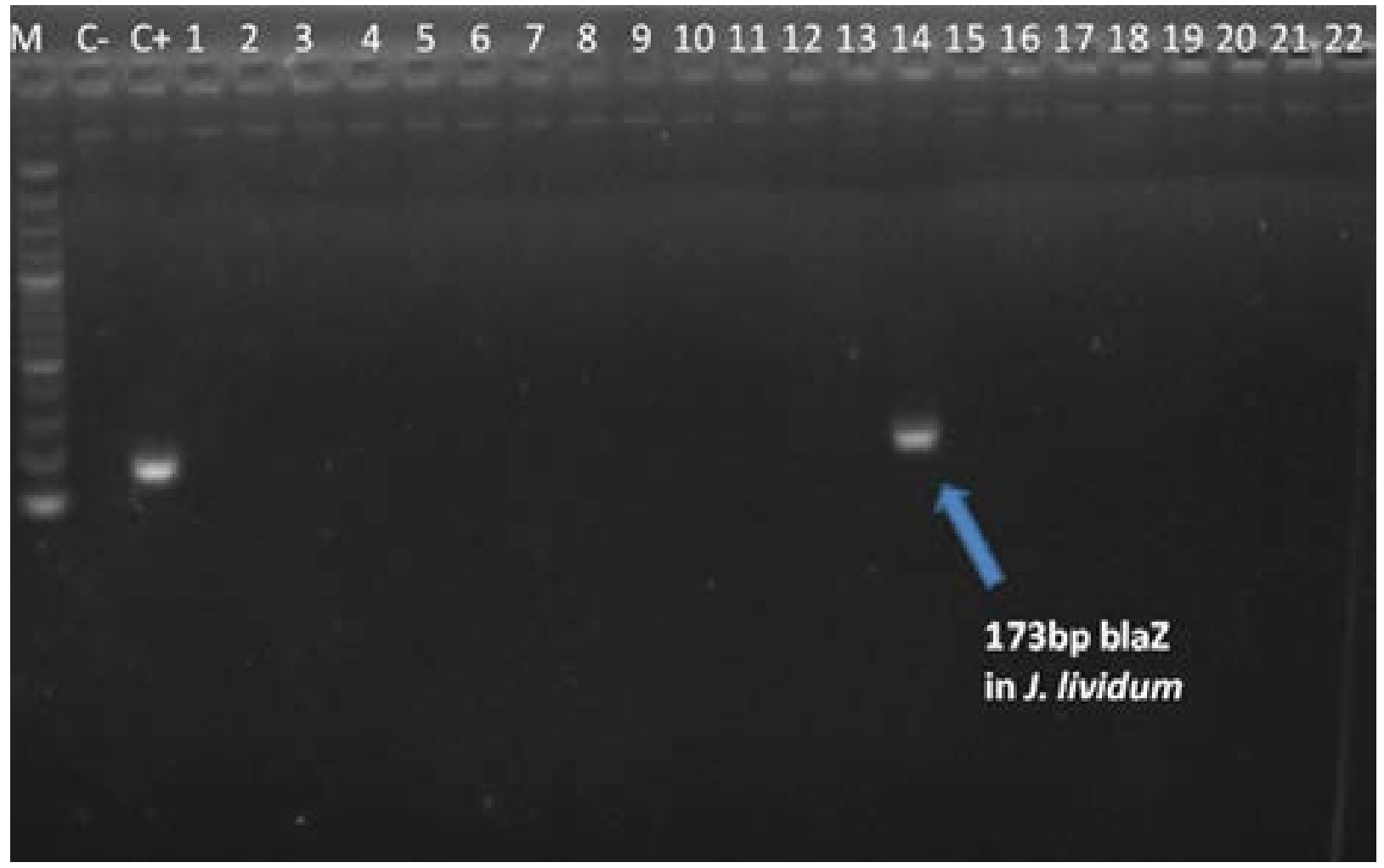

Figure 2: Amplification of 173bp blaZ resistance gene in J. lividum (M: 100bp marker)

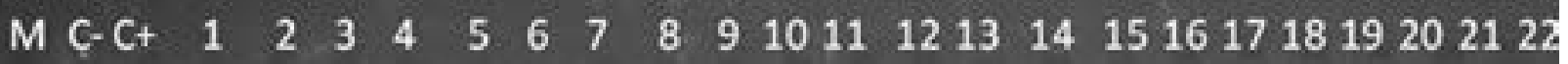

$174 \mathrm{bp}$ aac-

$\left(6^{\prime}\right)-\operatorname{aph}\left(2^{m}\right)$

Figure 3: Amplification of aac-(6')-aph-(2') resistance gene in J. lividum (M: 100bp marker) 
Table 4: Individual laboratory parameters of neonates with J. lividum septicaemia $(\mathrm{n}=22)$

\begin{tabular}{llllll}
\hline $\begin{array}{l}\text { WBS } \\
\text { (cells/L) }\end{array}$ & $\begin{array}{l}\text { ANC } \\
\text { (cells/L) }\end{array}$ & nRBC (\%) & $\begin{array}{l}\text { Platelets } \\
\text { (cells/L) }\end{array}$ & $\begin{array}{l}\text { IT ratio } \\
\text { IG/TNC }\end{array}$ & $\begin{array}{l}\text { CRP } \\
\text { (mg/dl) }\end{array}$ \\
\hline 2810.00 & 1690.00 & 1.00 & 22000.00 & .21 & 1.70 \\
21350.00 & 15120.00 & 1.00 & 217000.00 & .09 & .20 \\
24300.00 & 1230.00 & 6.00 & 282000.00 & .17 & .40 \\
22470.00 & 15270.00 & 1.00 & 278000.00 & .09 & 1.60 \\
21780.00 & 16420.00 & .00 & 167000.00 & .28 & 6.00 \\
6500.00 & 3200.00 & 15.00 & 90000.00 & .09 & .80 \\
19460.00 & 10900.00 & .00 & 282000.00 & .02 & 20.80 \\
25550.00 & 19930.00 & 5.00 & 249000.00 & .10 & .30 \\
24190.00 & 16940.00 & .00 & 327000.00 & .11 & 2.80 \\
6260.00 & 2620.00 & .00 & 195000.00 & .05 & .20 \\
26040.00 & 19040.00 & 1.00 & 170000.00 & .03 & .20 \\
11760.00 & 5710.00 & 3.00 & 159000.00 & .02 & 1.60 \\
11760.00 & 5720.00 & 5.00 & 162000.00 & .13 & 1.60 \\
16140.00 & 12720.00 & 4.00 & 232000.00 & .29 & 2.90 \\
10020.00 & 30030.00 & 9.00 & 196000.00 & .06 & .20 \\
9710.00 & 3310.00 & 15.00 & 145000.00 & .05 & .20 \\
11540.00 & 4710.00 & 6.00 & 145000.00 & .13 & 7.80 \\
15130.00 & 9180.00 & .00 & 56000.00 & .02 & 1.90 \\
19900.00 & 10020.00 & 11.00 & 298000.00 & .08 & 1.90 \\
8850.00 & 820.00 & 7.00 & 224000.00 & .13 & .20 \\
8180.00 & 820.00 & .00 & 224000.00 & .04 & .20 \\
2810.00 & 1690.00 & 1.00 & 22000.00 & .21 & 1.70 \\
\hline
\end{tabular}

Reference values: White blood cell count (WBC): or $\leq 5000 / \mathrm{mm}^{3}$ or $\geq 25000,30000$ and $21000 / \mathrm{mm}^{3}($ at birth, $12-24$ hours and 48hours).Absolute Neutrophils Count (ANC): Corrected WBC count (if correction required) $\times(\%$ Segmented neutrophil + immature granulocytes)/100 Nucleated red blood cells (nRBCs): Immature to total neutrophil ratio: $>0.2$ Platelets: $\leq 150,000 \mathrm{C}-$ reactive protein $(\mathrm{CRP}):>$ $5.0 \mathrm{mg} / \mathrm{dl}$

\section{Antibiotic resistance assay}

All extracted DNA of J. lividum strains were tested for resistance to Penicillin and Gentamicin by means of the blaZ and aac (6')-aph (2') specific PCR assays in Figure
4. Gentamycin-resistant was not found in all strains analyzed. However, one strain showed the 173bp of blaZ (gene in penicillin resistant) PCR amplicon (Figure 3). Subsequent DNA homology searches performed using the DNA sequences confirmed the result. 
Janthinobacterium lividum strain $\mathrm{HC}-316 \mathrm{~S}$ ribosomal RNA gene, partial sequence Sequence ID: gblkFpgas 15.11 Length: 1433 Number of Matches: 1

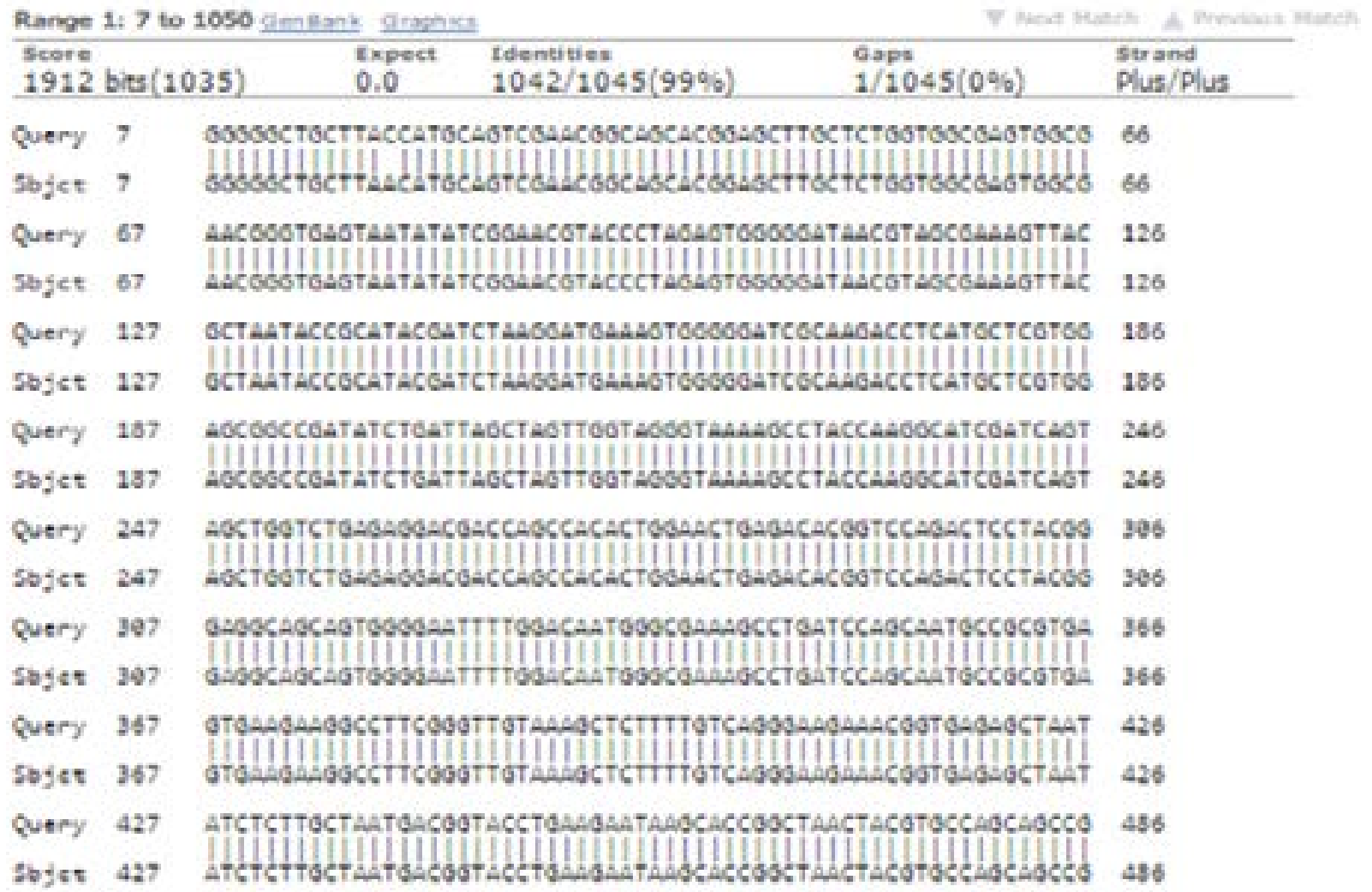

Figure 4: The sequence of the purified PCR product showing 99\% identity to the Gene Bank Sequence (Accession No: KF 993615.1) as Janthinobacterium lividum Sequence the homology of $16 \mathrm{~S}$ ribosomal RNA fragment with HC-3. $($ Length $=1433)$

Table 5: Laboratory parameters of neonates with J. lividum septicaemia $(n=22)$

\begin{tabular}{ll}
\hline Laboratory parameter & results \\
\hline WBC(cells/L) median [range] & $13360[23330]$ \\
ANC (cells/L), median [range] & $9180[29210]$ \\
nRBC (\%), median [range] & $2[15]$ \\
Platelets (cells/L) mean \pm SD & $195652[78963]$ \\
I:T ratio (\%), median [range] & $0.882[0.27]$ \\
CRP(mg/dl), median [range] & $1.6[20.60]$ \\
\hline
\end{tabular}

$\mathrm{WBC}=$ white blood cells; $\mathrm{ANC}=$ absolute neutrophil count $\mathrm{nRBC}=$ nucleated red blood cells; $\mathrm{I}: \mathrm{T}=$ proportion of immature -to-total neutrophils 


\section{Discussion}

J. lividum is one of the common bacteria found in the environment. Closely related bacteria Chromobacterium violaceum has been reported in several human infections, no available report on Janthinobacterium lividum contributing to EONS. Despite the fact that this result has not been previously described, the researchers are convinced about its acceptability because all the sequences of the amplicon were $100 \%$ identical to J. lividum sequence as shown in Figure 4. Basic description of genus Janthinobacterium was given by Sneath in 1984. It is a Gram negative, motile aerobic bacterium found in soil and waters (rivers, lakes and springs) $)^{7-9}$ and it was also reported in the spoilage of pasteurized milk ${ }^{10}$. Unlike other bacteria, J. lividum is unique in its incubation temperature. Although $96 \%$ of the Janthinobacterium strain can grow at $4^{\circ} \mathrm{C}$, the optimal temperature for growth in the laboratory is $25^{\circ} \mathrm{C}$. Therefore, it is not surprising if cultures for these bacteria yielded no growth since Janthinobacterium can never grow at $37^{\circ} \mathrm{C}^{11}$. Molecular studies such as PCR and sequencing on new-born had demonstrated more microbial causes of septicaemia than that shown by conventional culture method $^{12-14}$. J. lividum formally known as Chromobacterium lividum is a violet-pigment producing gram negative rod which is motile and survived in oxygen rich environment. It is mostly found in the tropical and subtropical regions usually in soil, water, and occasionally in putrid food as well as on the leaf nodule of a plant.

There was a report on fatal human infection with these bacteria from Thailand causing hospital acquired septicaemia in adult ${ }^{15}$. It was reported to be among unreported bacteria causing ventilator associated pneumonia on patients who were intubated and on mechanical ventilation $^{16}$. This observation was supported by previous report of J. lividum among the ignored bacterial flora inhabiting medical devices and work places within the $\mathrm{NICU}^{17}$. Interestingly, this study was conducted in neonates aged less than 48 hours old who presented with sign and symptoms of infection prior to their admission. Bacterial causes of EONS unless otherwise proven, are acquired from the mother rather than the environment. It might have been assumed that the infection is acquired within the NICU from medical devices, since most of the neonates under study were either on Nasal Continuous Positive Airway Pressure (NCPAP) or ventilator support, however, all neonates were admitted to the neonatal intensive care units immediately after birth and were already having symptoms suggesting early onset sepsis.

The infection could have been acquired maternally as there were reports of these bacteria from the cases of bacterial vaginosis ${ }^{18}$. Earlier than this, J. lividum was reported as part of vaginal microbial communities within individuals ${ }^{19}$. Most of the study population who were found to have positive PCR analysis for J. lividum, had at least one of the risk factors that predisposed them to infection including leaking liquor, meconium stained liquor, maternal urinary tract infection and premature rupture of membrane. These factors may cause them to be vulnerable to infection since it is confirmed to be inhabitant of women's genital tract.

Analysis of blood culture negative clinical samples using broad range real time PCR and subsequent sequencing, detected J. lividum in cases where bacterial infection were highly suspected but remained negative by culture ${ }^{20}$.The bacteria were not isolated by culture in this study. This was similarly reported by other researchers ${ }^{16-19}$. The possible reason why J. lividum failed to be isolated by conventional culture method may be attributed to the incubation temperature. All incubations are usually done at $37^{\circ} \mathrm{C}$ while J. lividum only grow at $25^{\circ} \mathrm{C}^{21}$. Several earlier studies reported the identification of J. lividum by $16 \mathrm{~S}$ rRNA PCR except study by Patijanasoontorn et $\mathrm{al}^{15}$ who isolated the bacteria by culture. However did not reveal the culture technique. A study from Thailand reported septicaemia caused by J. lividum with high fatality rate. Nonetheless, no patients with J. lividum infection in this study died as a result of sepsis. The potential reason could be due to prompt antibiotic administration to all clinically suspected sepsis among neonates who were admitted to NICU. To further confirm this, DNA samples from $22 \mathrm{~J}$. lividum positive samples were subjected to antibiotic resistance assays. However, none of the 22 samples was found to have resistance gene to Gentamicin while one strain was found to have resistance gene to Penicillin but not having resistance gene to Gentamycin. These neonates were treated with the two antibiotics based on the suspicion of having neonatal sepsis.

\section{Limitations}

Tracing the source of these bacteria would have revealed useful information about its role in causing early onset neonatal sepsis, but this was not evaluated mainly due to financial constraint. 


\section{Conclusion}

J. lividum has not been reported in neonates or any NICU in Malaysia. This is the first report of this specie in neonatal blood. It is mostly of nosocomial origin and possibly colonized mothers in the hospital. Although there were no cases of neonatal infection with these bacteria, nosocomial infection with J. Lividum clearly occurred in a hospital intensive care unit in Thailand ${ }^{15}$. Therefore, this highlights the need for infection control practices by the health care workers to prevent future occurrence. Furthermore, these findings demonstrate the value of PCR in clinical settings. Though PCR cannot displace culture, it certainly offers improvement in the diagnosis of bacterial infection especially when bacteria with special growth requirement are involved.

\section{Disclosure statement}

None to declare.

\section{Acknowledgments}

Thanks to Shahrul Adahar B. M.D Hassan and Nurhafiza Binti Saufi for excellent technical assistance.

\section{Funding}

This work was supported by a grant from the Universiti Putra Malaysia (04-05-11-1585RU).

\section{References}

1. Fleischmann-Struzek C, Goldfarb DM, Schlattmann P, Schlapbach LJ, Reinhart K, Kissoon N. The global burden of paediatric and neonatal sepsis: a systematic review. Lancet Respir Med. 2018; 6:223-30.

2. Chaurasia S, Sivanandan S, Agarwal R, Ellis S, Sharland M, Sankar MJ. Neonatal sepsis in South Asia: huge burden and spiralling antimicrobial resistance. BMJ. 2019;364:k5314.

3. Ghosh S, Basu G. A hospital based study on clinico microbiological profile of neonatal septicemia. Asian J. Med. Sci. 2018;9:25-30. PubMed

4. Datta S, Anand RP, Ghosh P. Neonatal sepsis-organisms responsible as detected by blood culture. J Evol Med Dent Sci. 2017 Jul 20;6:4327-32.

5. Baker G, Smith J, Cowan DA. Review and re-analysis of domain-specific 16S primers. J Microbiol Methods. 2003;55(3):541-55.

6. Martineau F, Picard FJ, Grenier L, Roy PH, Ouellette M, Bergeron MG. Multiplex PCR assays for the detection of clinically relevant antibiotic resistance genes in staphylococci isolated from patients infected after cardiac surgery. J Antimicrob Chemother. 2000;46(4):527-34.

7. Johnson JH, Tymiak AA, Bolgar MS. Janthinocins A, B and $\mathrm{C}$, novel peptide lactone antibiotics produced by Janthinobacterium lividum. II. Structure elucidation. I Antibiot. 1990;43(8):920-30.

8. O'Sullivan J, McCullough J, Johnson JH, Bonner DP, Clark JC, Dean L, et al. Janthinocins A, B and C, novel peptide lactone antibiotics produced by Janthinobacterium lividum. I. Taxonomy, fermentation, isolation, physico-chemical and biological characterization. I Antibiot. 1990;43(8):913-9.

9. Rossolini GM, Condemi MA, Pantanella F, Docquier J-D, Amicosante G, Thaller MC. Metallo- $\beta$-lactamase producers in environmental microbiota: new molecular class B enzyme in Janthinobacterium lividum. Antimicrob Agents Chemother. 2001;45(3):837-44.

10. Eneroth A, Ahrné S, Molin G. Contamination routes of Gram-negative spoilage bacteria in the production of pasteurised milk, evaluated by randomly amplified polymorphic DNA (RAPD). Int Dairy J. 2000;10(5):325-31.

11. Gillis M, De Ley J. The genera Chromobacterium and Janthinobacterium. The Prokaryotes: Volume 5: Proteobacteria: Alpha and Beta Subclasses. 2006:737-46.

12. Jones V, Wilks M, Johnson G, Warwick S, Hennessey E, Kempley S, et al. The use of molecular techniques for bacterial detection in the analysis of gastric aspirates collected from infants on the first day of life. Early Hum Dev. 2010;86(3):167-70.

13. Jordan JA, Jones-Laughner J, Durso M. Utility of pyrosequencing in identifying bacteria directly from positive blood culture bottles. J Clin Microbiol. 2009;47(2):368-72. 14. Esparcia O, Montemayor M, Ginovart G, Pomar V, Soriano G, Pericas R, et al. Diagnostic accuracy of a $16 \mathrm{~S}$ ribosomal DNA gene-based molecular technique (RTPCR, microarray, and sequencing) for bacterial meningitis, early-onset neonatal sepsis, and spontaneous bacterial peritonitis. Diagn Microbiol Infect Dis. 2011;69(2):153-60.

15. Patijanasoontorn B, Boonma P, Wilailackana C, Sitthikesorn J, Lumbiganon P, Chetchotisakd P, et al. Hospital acquired Janthinobacterium lividum septicemia in Srinagarind Hospital. J Med Assoc Thai. 1992;75:6-10.

16. Bahrani-Mougeot FK, Paster BJ, Coleman S, Barbuto S, Brennan MT, Noll J, et al. Molecular analysis of oral and respiratory bacterial species associated with ventilator-associated pneumonia. J Clin Microbiol. 2007;45(5):1588-93. 
17. Oberauner L, Zachow C, Lackner S, Högenauer C, Smolle K-H, Berg G. The ignored diversity: complex bacterial communities in intensive care units revealed by $16 \mathrm{~S}$ pyrosequencing. Scientific Reports. 2013;3.

18. Lambert JA, Kalra A, Dodge CT, John S, Sobel JD, Akins RA. Novel PCR-based methods enhance characterization of vaginal microbiota in a bacterial vaginosis patient before and after treatment. Appl Environ Microbiol. 2013;79(13):4181-5.

19. Kim KA, Shin SM, Choi JH. A nationwide survey on the causative organisms of neonatal sepsis in Korea. $J$ Korean Pediatr Soc. 2002;45(1):55-63.

20. Schabereiter-Gurtner C, Nehr M, Apfalter P, Makristathis A, Rotter M, Hirschl A. Evaluation of a protocol for molecular broad-range diagnosis of culture-negative bacterial infections in clinical routine diagnosis. J Appl Microbiol. 2008;104(4):1228-37.

21. Pantanella F, Berlutti F, Passariello C, Sarli S, Morea C, Schippa S. Violacein and biofilm production in Janthinobacterium lividum. J Appl Microbiol. 2007;102(4):992-9. 